phosphate content was inversely proportional to the chlorophyll, but neither nitrate nor total phosphate showed any correlation with the pigments.

The quantities of pigments found off Sydney covered the range found on more extensive cruises in the Coral and Tasman Seas and in the Indian Ocean. On these cruises the importance of chlorophyll $c$ was again evident.
The results described in this paper are the first detailed observations of plankton pigments from Australian waters, collected in the extensive oceanographical programme which the Commonwealth Scientific and Industrial Research Organization in Australia is now undertaking, and they form an interesting basis for comparison with other regions.

R. I. CuRrit:

\title{
CENOZOIC MAMMALS IN NORTH AMERICA
}

\begin{abstract}
UST over one hundred yoars ago Charles Moore, an amateur geologist of Bath, washed and sieved three tons of clay to obtain 30 multicusped teeth : the clay was a Rhaeto-Liassic fissure infilling and the teeth were of Microlestes, and they remain to-day almost the only record of this raro group of animals astride the frontier that separates mammals and reptiles.

Despite this promising beginning, fow vertebrate palæontologists have taken to the labours of washing and sieving on a big scale. Jr. McKenna has been one and it has paid handsome dividonds; the washing and sieving of Wasatchian claystones and sandstones has yielded him 11,000 complete mammal teeth from a formation otherwise almost barron, and a horizon astride the Eocene and Palæocone all too poorly known. The complete dissociation of the remains is a considerablo limitation of the technique and Dr. M. C. MeKenna does not appear to have attempted any concentrating methods, the fossils being hand picked from sieved fractions (University of California Publications in Geological Scionces. 37, No. 1 : Fossil Mammalia from the Farly Wasatchian Four Mile Fauna, Eocene of Northwest Colorado. Pp. 1-130. (Berkeley and Los Angeles : University of California Press; London: Cambridgo University Press, 1960.) 2.50 dollars).

A fauna of 58 species from 12 mammalian orders is described; these include four multituberculates, a marsupial, several primates and insectivores. The fauna shows close similarity with those of early Gray Bull fauna of Wyoming, though there aro notable
\end{abstract}

absentees, and is considered early Wasatchian, that is, basal Eocene. The paper has no plates, but the text-figures are ample and exceptionally clear.

Pantodonta is an order of mammals the systematic study of which is fraught with difficulties; while distinction as an order is clear, the internal and oxternal affinities remain debatable. Rocent work by Dr. E. L. Simons is confined largely to the Palæeocone species of North America, albeit this comprises most of the described forms; the European Eocene and Asiatic Oligocene forms are mentioned in his discussions (Trans. Amer. Phil. Soc. (New Sories), 50, Part 6: The Paleocene Pantodonta. Pp. 99. (Philadelphia: American Philosophical Society, 1960.) 2.50 dollars). Dotailed diagnoses are givon for North American Palnocene species only. The post-cranial skeleton is described for most genera where it is known, with differences notod, but few comments on their significance: although approximat oly half this paper is devoted to skeletal anatomy, there is only one illustration of pelves. The wealth of material availablo makes it difficult to accept the quotation "thoy [Pantodonta] defy interpretation of their mode of life because they are so totally unlike anything now living" ; they are no more remote than Titanotheres and mammal-liko roptiles.

Biostratonomic work threw little light on the ccology of the pantodonts ; this is not surprising since their life habitat was probably quito different from their place of entombment. Concerning the relations to other orders, the author restates the main arguments used by earlier writors. R. J. G. SAVAGE

\section{EARTH SATELLITE OBSERVATIONS AND THE UPPER ATMOSPHERE}

\section{Temperature Inversion in the FI-Layer}

CUFHICIENTLY reliable values of atmospheric density-including the diurnal variations-in altitudes $200-700 \mathrm{~km}$. have been derived from the variations of the acceleration of artificial Earth satellites ${ }^{1-3}$. Measurements from rockets ${ }^{4,5}$ gave density values up to about $200 \mathrm{~km}$.

The densities obtained from rocket measurements and the satellite data could not be represented satisfactory by a single curve with monotonically varying gradient. Therefore, H. K. Kallmann ${ }^{6}$ suggested a modol which contains a 'wiggle' in the logarithmic density curve at altitudes $150-200 \mathrm{~km}$. It is model $C$ in her paper.

From the data ${ }^{7}$ from satollites $1958 \delta 2$ (Sputnik 3) and $1959 \zeta$ (Discoverer 6), it now became possible to derive the exact form of the 'wiggle'. Twenty values for atmospheric density at altitudes $180-235 \mathrm{~km}$. from the satellite $1959 \zeta$ and the numerous results from the satellite $1958 \delta 2$ during August 1959-April 6, 1960 , were available for this purpose. During this period the altitude of the perigee of the latter satellite decreased from $215 \mathrm{~km}$. to $147 \mathrm{~km}$. In order to eliminate seasonal effects, only values with $|\Delta \delta|=$ $\left|\delta_{\pi}-\delta_{\odot}\right|<60^{\circ}$ were used (where $\delta$ is doclination, $\pi$ is perigee, $O$ is Sun).

The atmospheric densities were first derived according to a method described in detail in our earlier paper $^{1}$; that is, preliminary values for atmospheric density were computed using the scale heights of H. K. Kallmann's "preliminary model"'. Then a linear approximation to the logarithmic density curve was derived graphically for altitudes where the major air drag on the satellite oceurs. The gradient of this linear approximation was employed to determine the final atmospheric densities, so that we havo an itera. 